\title{
Bilateral Ureteral Reimplantation and Psoas Hitch for Iatrogenic Injury of Ureters after Abdominal Hysterectomy in an Old Woman with Conventional Radiotherapy: A Case Report
}

\section{Cevdet Kaya* and Ahmet Şahan}

Department of Urology, School of Medicine, Marmara University, İstanbul, Turkey

\section{Introduction}

Iatrogenic ureteral trauma can result from various mechanisms such as ligation with a suture, crushing with a clamp, partial or complete transection, thermal injury and ischaemia from devascularisation [1]. Gynaecological operations are the commonest cause of iatrogenic trauma to the ureters and usually involve damage to the lower ureter [2]. Not only bilateral ureteral injury, but also bilateral simultaneous ureteral reimplantation after transabdominal hysterectomy in a patient already received radio/chemotherapy is extremely rare. In this case report, the management of bilateral ureteral injury for radical abdominal hysterectomy is discussed.

\section{Case Report}

A 68 year-old woman was presented to the emergency room with the symptoms of anuria and vaginal urine leak. In her past history, there was the radical abdominal hysterectomy and bilateral salpingoophrectomy for invasive endometrial adenocancer. Physical examination revealed moderate abdominal distention. Serum creatinine level was $0.9 \mathrm{ng} / \mathrm{ml}$. The urine analysis revealed no infection. Abdominal ultrasound showed bilateral hydronephrosis and it was diagnosed as bilateral complete ureteral injury resulting from the previous gynecological surgery. Then bilateral nephrostomy catheters was introduced, and following antegrade pyelography showing a lack of continuity of the ureter and the extravasation of the contrast material at both distal ureters. Since the definitive surgery was delayed after chemotherapy and radiotherapy, the reconstruction of both injured ureters was performed 9 months after the gynecological operation. Laparotomy showed that both of the ureters firmly attached to pelvic peritoneum and intestines in the pelvic cavity, and significant adhesions in the upper part of a midline incision from prior abdominal hysterectomy and radiotherapy. After releasing of these midabdominal adhesions, vaginal cuff was open and repaired with the use of omental flap. Following the dissection of the distal parts of the ureters, the occlusion of the lumen was noticed $5 \mathrm{~cm}$ on the left and $4 \mathrm{~cm}$ on the right from ureterovesical junction. Therefore, ureteral reimplantation with psoas hitch was performed on both sides. A $4.8 \mathrm{~F} 28 \mathrm{~cm}$ double-J stent was introduced through the renal pelvis. A $16 \mathrm{~F}$ Foley catheter was left in place for maximal drainage of the bladder during 7 days. The right and left nephrostomy tubes were removed in the postoperative days 6 and 7, respectively. Tube drain was removed on postoperative days 10. The Foley catheter was removed on post- operative day 7. Cystoscopy was performed for the removal of both double J stents after 6 weeks. We had satisfactory results with functional recovery and maintenance of function 2 months after surgery and absence of complications (Figure 1).

\section{Discussion}

Ureteral injury is one of the most serious complications of both open and laparoscopic gynecologic surgeries most probably because of the close anatomical relationship between urinary tract and female genital systems [3]. Iatrogenic trauma to the ureters is a troublesome condition and often associated with significant morbidity up to the potential loss

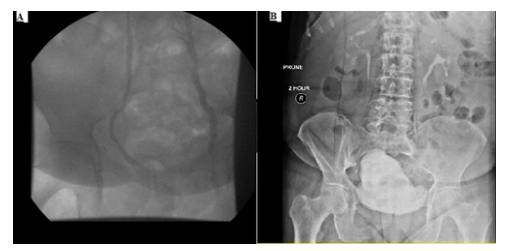

Figure 1: A) Preoperative antegrade pyelography showing a lack of continuity of the distal ureter. B) Postperative Intravenous pyelography with normal upper urinary tract and passage of contrast material to the bladder.

of kidney function, especially when not recognized perioperatively and in the early days of the postoperative period [4]. In addition to this evidence-based morbidity of this complication, injuries to the urinary tract, particularly the ureter, are the most common cause for legal action against gynecologists $[1,5]$. When we look at the mechanisms of trauma, we can identify that the ligation or kinking with a suture, crushing by a clamp, partial or complete transection, thermal injury, or ischaemia from devascularisation can occur in an open or laparoscopic gynecological surgery, even in the most experienced surgeon's hands [2]. One of the main problems in such cases is that a diagnostic delay of about 36 hours or longer has been observed in more than $50 \%$ of trauma patients [4]. Prompt detection and early repair is necessary to prevent the functional loss of the affected kidney and associated morbidities. Abdominal ultrasonography and delayed-phase contrastenhanced CT scan are recommended for early diagnosis in suspected cases of ureteral injury [6]. Therefore, in the case of an ureteral injury during the gynecological operation does occur, very quick recognition of the presence of trauma and its location, and the following the critical clinical decision step, the management of this challenging condition are essential in providing patients with optimal medical care.

Reconstructive ureteral surgeries, similar to our case, should be performed in experienced centers, where all the alternative surgical procedures from ureteroureterostomy up to Boari flap to manage ureteral injury can be applied.

*Corresponding author: Cevdet Kaya, Department of Urology, School of Medicine, Marmara University, İstanbul, Turkey, Tel: +90 216414 0545; E-mail: drckaya@hotmail.com

Received October 28, 2015; Accepted November 23, 2015; Published December 01, 2015

Citation: Kaya C, Şahan A (2015) Bilateral Ureteral Reimplantation and Psoas Hitch for latrogenic Injury of Ureters after Abdominal Hysterectomy in an Old Woman with Conventional Radiotherapy: A Case Report. J Trauma Treat 4: 273. doi:10.4172/2167-1222.1000273

Copyright: ( 2015 Kaya C, et al. This is an open-access article distributed under the terms of the Creative Commons Attribution License, which permits unrestricted use, distribution, and reproduction in any medium, provided the original author and source are credited. 
Citation: Kaya C, Şahan A (2015) Bilateral Ureteral Reimplantation and Psoas Hitch for latrogenic Injury of Ureters after Abdominal Hysterectomy in an Old Woman with Conventional Radiotherapy: A Case Report. J Trauma Treat 4: 273. doi:10.4172/2167-1222.1000273

Page 2 of 2

\section{References}

1. Esparaz AM, Pearl JA, Herts BR, LeBlanc J, Kapoor B (2015) latrogenic urinary tract injuries: etiology, diagnosis, and management. Semin Intervent Radiol 32 195-208.

2. Aslan $P$, Brooks $A$, Drummond $M$, Woo $H$ (1999) Incidence and management of gynaecological-related ureteric injuries. Aust N Z J Obstet Gynaecol 39: 178-181.

3. Mendez LE (2001) latrogenic injuries in gynecologic cancer surgery. Surg Clin North Am 81: 897-923.
4. Lucarelli G, Ditonno P, Bettocchi C, Grandaliano G, Gesualdo L, et al. (2013) Delayed relief of ureteral obstruction is implicated in the long-term development of renal damage and arterial hypertension in patients with unilateral ureteral injury. J Urol 189: 960-965.

5. Burks FN, Santucci RA (2014) Management of iatrogenic ureteral injury. Ther Adv Urol 6: 115-124.

6. Teber D, Egey A, Gözen AS, Rassweiler J (2005) Ureteral injuries. Diagnostic and treatment algorithm. Urologe A 44: 870-877. 